\title{
Facial Nerve Function after Large Cystic Vestibular Schwannomas Surgery via the Retrosigmoid Approach
}

\author{
Retrosigmoid Yaklaşımla Büyük Kistik Vestibüler Schrwannom \\ Cerrahisinden Sonra Fasiyal Sinir Isslevi
}

\author{
Minqing WANG, Deze JIA, Jie SHEN, Jian ZHANG, Gang LI \\ Qilu Hospital of Shandong University, Department of Neurosurgery, Jinan/Shandong Province, P.R. China
}

Correspondence address: Gang LI / E-mail: doctorligang@126.com

\begin{abstract}
AIM: To evaluate long-term postoperative facial nerve function in patients undergoing large cystic vestibular schwannomas (VSs) surgery. MATERIAL and METHODS: Surgical outcome of 36 patients with large cystic VS was retrospectively assessed, and compared with a group of 67 patients with large solid VS.

RESULTS: The anatomical integrity of the facial nerve was preserved in $88.9 \%$ of cystic group patients and in $92.5 \%$ of solid group patients. At 1 year after surgery, $75.8 \%$ of the patients with cystic VSs had favorable facial nerve function and $24.2 \%$ had poor function. There was no significant difference in facial nerve outcomes between cystic and solid tumors. When the cyst wall was closely adherent to the facial nerve, near total or subtotal resection was associated with a better facial nerve outcome compared to total excision $(P<0.05)$.

CONCLUSION: In most cystic VS patients, favorable facial nerve function can be attained by surgical treatment via retrosigmoid approach. Special care should be taken to remove entire cystic VSs as well as partial cystic VSs with anterior or medial located cysts. When a dissection plane cannot be developed between the cyst wall and the facial nerve, near total or subtotal resection is of benefit for facial nerve function.

KEYWORDS: Vestibular schwannoma, Cystic, Retrosigmoid approach, Facial nerve outcomes
\end{abstract}

öz

AMAÇ: Büyük kistik vestibüler schwannom (VS) cerrahisi yapılan hastalarda uzun dönemli postoperatif fasiyal sinir işlevini değerlendirmek. YÖNTEM ve GEREÇLER: Büyük kistik VS durumu olan 36 hastada cerrahi sonuç retrospektif olarak değerlendirildi ve büyük solid VS olan 67 hastalık bir grupla karşılaştırıldı.

BULGULAR: Fasiyal sinirin bütünlüğü kistik grup hastalarının \%88,9 ve solid grup hastalarının \%92,5'inde korundu. Cerrahiden bir yıl sonra kistik VS hastalarının \% 75,8'inde olumlu ve \%24,2'sinde zayıf fasiyal sinir işlevi vardı. Kistik ve solid tümörler arasında fasiyal sinir sonuçları açısından anlamlı farklar yoktu. Kist duvarı fasiyal sinire çok yakından tutunmuş olduğunda totale yakın veya subtotal rezeksiyon total eksizyondan daha iyi bir fasiyal sinir sonucuyla ilişkiliydi $(\mathrm{P}<0,05)$.

SONUÇ: Çoğu kistik VS hastasında retrosigmoid yaklaşımla cerrahi tedavi yoluyla olumlu fasiyal sinir işlevi elde edilebilir. Tüm kistik VS'leri ve ayrıca anterior veya medial bulunan kistleri olan kısmi kistik VS'leri çıkarmaya özellikle dikkat edilmelidir. Kist duvarı ile fasiyal sinir arasında bir diseksiyon düzlemi oluşturulamadığında, fasiyal sinir işlevi açısından totale yakın veya subtotal rezeksiyon faydalıdır.

ANAHTAR SÖZCÜKLER: Vestibüler schwannom, Kistik, Retrosigmoid yaklaşım, Fasiyal sinir sonuçları

\section{INTRODUCTION}

Vestibular schwannomas (VSs) are benign and slow-growing tumors originating from the vestibular part of the eighth cranial nerve $(23,27)$. In developed countries, most VSs are diagnosed in their small, early stages with modern imaging technology. But in China, large VSs measuring $>3.0 \mathrm{~cm}$ are more common due to the less developed economy and healthcare system (27). Microsurgery is considered the treatment of choice in large VSs, but complete resection of the tumor often carries a considerable risk of facial nerve damage, and good facial nerve function (HB Grade I or II) is reported in only $27 \%-58 \%$ of patients $(1,6)$. Previous studies have documented that cystic degeneration in VSs was related to poor facial nerve outcome $(2,4,20)$. Although extensive cystic changes in VSs are relatively uncommon, it is more frequent in large tumors than tumors of smaller size $(7,11,25)$. In an attempt to assess postoperative facial nerve function in cases of large cystic VSs, we analyzed the surgical results in a consecutive series of patients with such tumors. Particular emphasis has been put on long-term facial nerve outcome 
and a comparison with a group of patients with large solid VS surgically treated during the same period at our institution was also performed.

\section{MATERIAL and METHODS}

\section{Patients and Presention}

A retrospective study of surgical outcome was performed on 103 consecutive patients with large VS (more than or equal to $3.0 \mathrm{~cm}$ in the greatest extrameatal diameter) who were surgically treated between March 2005 and March 2010. Preoperatively, all patients underwent plain and enhanced magnetic resonance imaging (MRI) scans except for 3 patients who had diagnostic consideration of epidermoid cyst and did not get enhanced MRI images. Histopathological examination verified VS in these 3 patients. Two groups of tumors were separated: a group of 36 cystic VSs and a group of 67 solid VSs. The cohort of 36 tumors was defined as cystic tumors according to the following criteria: 1) presence of hypointense areas without enhancement on contrast-enhanced T1weighted image, 2) intraoperative identification of cystic elements, 3) cystic change involving more than $30 \%$ of tumor on gross examination. The volume of the tumor and cyst were estimated according to the method described by Mehrotra $\mathrm{N}$ (11). Based on the degree of cystic change (total and partial) and the cyst characteristics (monocystic or multicystic), four types of cystic VSs were identified: Type A1 monocystic partial cystic VS, which is characterized by a single cyst within tumor (Figure 1A). Type A2 multicystic partial cystic VS, which is present as multiple cysts within tumor (Figure 1B). Type B1 monocystic entire cystic VS, which is composed by a large single cyst surrounded by a thin wall or small amount of peripheral solid tissue (Figure 1C). Type B2 multicystic entire cystic VS, which is purely composed of multiple cysts (Figure 1D). Cystic VSs of this study included Type $A$ in 25 patients (11 monocystic and 14 multicystic VSs) and Type B in 11 patients (4 monocystic and 7 multicystic VSs).

Cystic Group: There were 15 males and 21 females, with their age ranging from 31 to 76 years (mean 51.2 years). The tumors were located in the right side in 19 cases and in the left in 17 cases. The mean extrameatal size of the tumors was $4.6 \pm 0.8 \mathrm{~cm}$. The duration of initial symptoms prior to definitive diagnosis was between 1 month and 7 years (mean 24.2months). In 21 cases the initial symptom that led the patients to medical referral was hearing dysfunction. Atypical initial symptoms presented in 15 cases including headache (5), trigeminal hypoesthesia (4), facial palsy (1), unsteadiness (1), vertigo (2) and visual deficit (2). Preoperatively, ten patients had facial nerve dysfunction: 6 had HB Grade II function, 3 had HB Grade III function, and 1 had HB Grade IV. 19 patients had symptoms of increased intracranial pressure with radiologically-verified obstructive hydrocephalus.

Solid Group: There were 27 males and 40 females with a mean age of 49.7 years (range 24-77). The time from onset of symptoms to diagnosis ranged from 20 days to 15 years, with a mean of 60.7 months. The mean extrameatal size of the tumors was $4.5 \pm 0.7 \mathrm{~cm}$. Hearing impairment was the most common initial symptom, which presented in 54 patients. In 13 cases, an atypical initial symptom such as headache, vertigo, trigeminal hypoesthesia, facial palsy and unsteadiness, presented. Preoperatively, 16 patients had facial nerve palsy: HB Grade II in 9 patients, Grade III in 4 and Grade IV in 3. Radiological evidence of hydrocephalus was demonstrated in 21 patients.

\section{Surgical Procedures and Outcome Measures}

All patients were treated using a standardized microsurgical technique and the retrosigmoid suboccipital approach, and underwent surgery by the same surgeon (G.L.). Details of the surgical technique have been described previously $(26,27)$. Since 2009, intraoperative electrophysiological monitoring has been routinely utilized. During the operation, we focus on the following points to avoid the damage of the facial nerve: 1 ) greater cerebellar retraction is not required for cystic tumors because CSF release and drainage of cyst content can achieve a better exposure; 2) facial nerve should be carefully separated from the tumor by using a sharp dissection; 3 ) When the tumors adhere firmly to the facial nerve and brainstem, a little amount of residual tumor capsule is left; 4) Bipolar coagulation should be performed rarely and at low intensity.

Facial nerve function was assessed using the HouseBrackmann (HB) facial nerve function grading scale. Facial nerve function was evaluated at the time of discharge, and at 1 year after surgery. The patients were divided into two subgroups: favorable facial nerve function (HB Grades I-III) and poor facial nerve function (HB Grades IV-VI) $(5,14)$. The extent of tumor removal was initially judged by the surgeon and confirmed by postoperative CT or MRI. The degree of resection was classified as gross total resection (GTR), near total resection (NTR), and subtotal resection (STR). NTR was defined as over $95 \%$ resection leaving remnants of intra-meatal tumor or tumor adhering to the facial nerve or brainstem. STR was defined as over $90 \%$ resection of the tumor (13).

\section{Statistical Analysis}

The statistical package SPSS 13.0 (SPSS, Chicago, IL, USA) was used for all analyses. Continuous variables were compared using an independent student's t-test. Binary variables were compared using Pearson's $x 2$ test. Logistic regression was performed on favorable facial nerve function to assess the influence of subtotal resection, age and tumor size $(\geq 45 \mathrm{~mm})$. Odds ratios were calculated and statistical significance was determined if $\mathrm{P}<0.05$.

\section{RESULTS}

\section{General}

The mean duration of symptoms for the cystic tumors was shorter than the solid tumors, and the incidence of atypical initial symptoms and preoperative hydrocephalus were significantly high in cystic tumors. During the operation, blood transfusion was necessary in 4 of patients with cystic VSs and 

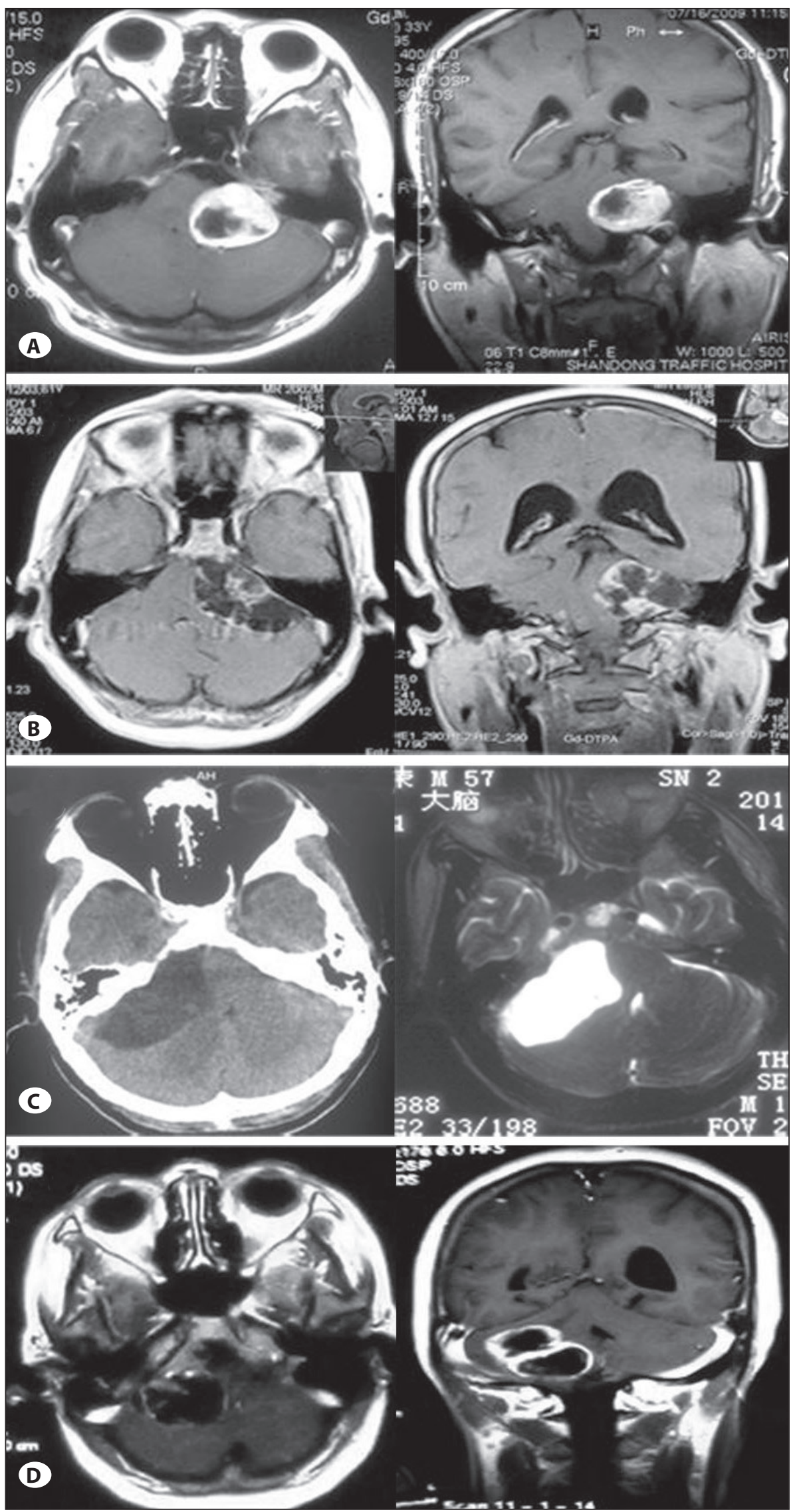

Figure 1: Classification of cystic VSs based on the degree of cyst change and cyst number. A: Type A1, B: Type A2, C: Type B1, D: Type B2. 
14 of patients with solid VSs. Severe adhesion to the facial nerve was found in 23 cystic VSs and 25 solid VSs. In cystic group, GTR was performed in $21(58.3 \%)$ of the 36 patients, NTR in 8 (22.2\%), and STR in 7 (19.4\%). Among patients that underwent STR, portions of tumor capsule were leave in situ with the facial nerve ( 2 facial nerve, 5 facial nerve and brainstem). In solid group, GTR was performed in 53 (79.1\%) of the 67 patients, NTR in 8 (11.9\%), and STR in $6(12.8 \%)$. There was one death $(2.8 \%)$ in cystic group. No recurrences have been observed in patients with cystic tumor. One patient with solid VS developed recurrent tumor, the patient was treated by stereotactic radiosurgery.

\section{Postoperative Facial Nerve Function}

In the cystic group the rate of anatomic preservation of the facial nerve was $88.9 \%$. In four cases, the facial nerve was closely adherent to the tumor and was not preserved, but they all got total tumor resection. The assessment of facial nerve function is shown in Table I. Five patients had complete facial palsy after surgery, including those with loss of the anatomical integrity of the nerve. At discharge, 23 (65.7\%) patients had favorable facial nerve function, 12(34.3\%) patients had unfavorable facial nerve function. At 1 year follow-up, $75.8 \%$ of all patients had favorable facial nerve function, $24.2 \%$ had poor function. 19 patients (82.6\%) with Type A cystic tumors had favorable facial outcomes, and 4 (17.4\%) had unfavorable outcomes. 6 patients (60\%) with Type B cystic tumors had favorable outcomes, and 4 (40\%) had poor facial nerve outcomes. In solid group: The continuity of the facial nerve was preserved in 62 patients (92.5\%). The assessment of facial nerve function was shown in Table I. There was no significant difference in postoperative facial nerve function between cystic and solid tumor group at discharge or 1 year follow-up ( $P=0.878, P=0.304)$. Among cystic VSs with severe adhesion to the facial nerve, 12 of 15 cases with STR or NTR had favorable facial nerve function at discharge, but only 1 case in the complete resection group had a favorable facial nerve outcome $(P=0.002)$. Using logistic regression analysis with a primary outcome measure of HB Grades I-III in both cystic and solid VSs, we found that only smaller tumor size $(P=0.044$, odds ratio $=2.71)$ was significant, and there may be a trend for subtotal resection $(P=0.071$, odds ratio $=0.30)$.

\section{Complications}

A summary of postoperative complication in both groups is listed in Table II. One patient out of 103 died in the postoperative period: this was a 56-year-old woman with a cystic tumor, who died due to post-operative hematoma. The most common complication was lower cranial nerves deficits, which occurred in 2 (5.6\%) patients affected by cystic VS and in $6(9.0 \%)$ patients with solid VS, and the nerve dysfunction was mostly temporary and mild. Followed by the CSF leak that occurred in 2 (5.6\%) of patients with cystic VS and 4 (6.0\%) of patients with solid VS. The CSF leak was resolved with lumbar puncture or a lumbar drain. 1(2.8\%) of cystic VS patients and 2 (3.0\%) of solid VS patients developed bacterial meningitis that

Table I: Facial Nerve Outcome After Excision of Large Vestibular Schwannoma in Both Groups Using the House-Brackmann Facial Nerve Grading Scale

\begin{tabular}{l|c|c|c|c|}
\multirow{2}{*}{ HB grade } & \multicolumn{2}{|c|}{ Cystic tumor (35) } & \multicolumn{2}{c|}{ Solid tumor (67) } \\
\cline { 2 - 5 } & At discharge (\%) & At 1 year (\%) & At discharge (\%) & $10(14.9)$ \\
\hline I & $4(11.4)$ & $5(15.2)$ & $16(23.9)$ & $18(28.1)$ \\
\hline III & $8(22.9)$ & $10(30.3)$ & $17(25.4)$ & $15(23.4)$ \\
IV & $11(31.4)$ & $10(30.3)$ & $11(16.4)$ & $8(12.5)$ \\
V & $5(14.3)$ & $3(9.1)$ & $6(9.0)$ & $4(6.3)$ \\
VI & $2(5.7)$ & $2(6.1)$ & $7(10.4)$ & $6(9.4)$ \\
\hline total & $5(14.3)$ & $3(9.1)$ & 67 & 64 \\
\hline
\end{tabular}

Table II: Cystic Versus Solid Vestibular Schwannomas: Complications and Mortality

\begin{tabular}{|l|c|c|}
\hline Complications & $\begin{array}{c}\text { Cystic tumors (36) } \\
\text { Number of patients (\%) }\end{array}$ & $\begin{array}{c}\text { Solid tumors (67) } \\
\text { Number of patients (\%) }\end{array}$ \\
\hline Meningitis & $1(2.8)$ & $2(3.0)$ \\
\hline Lower cranial nerve paresis & $2(5.6)$ & $6(9.0)$ \\
\hline CSF leak & $2(5.6)$ & $4(6.0)$ \\
\hline Postoperative hematoma & $1(2.8)$ & $0(0)$ \\
\hline Cerebral edema & $1(2.8)$ & $1(1.5)$ \\
\hline Chest infection & $0(0)$ & $2(3.0)$ \\
\hline Mortality & $1(2.8)$ & $0(0)$
\end{tabular}


treated successfully with antibiotics. There was no significant difference in the frequency of complications and mortality in the two groups.

\section{DISCUSSION}

Cystic VSs differ from solid ones by atypical initial symptoms, shorter symptom duration, sudden neurological deterioration and more frequent facial nerve involvement $(2,4,11,14,23)$. Moreover, cystic VSs are thought to display rapid growth, and therefore these tumors often present with larger tumors (7). Contemporary treatment strategies for VSs consist of microsurgical resection, radiosurgery, watchful waiting or a combination of these modalities. Because of the large tumor size at diagnosis and reported cases of cyst swelling after radiosurgery (RS), microsurgical resection is the treatment of choice in cystic VSs $(2,4)$. However, previous studies suggested that cystic VSs had worse surgical outcomes compared to solid tumors, especially in the postoperative facial nerve function. Fundova et al. (4) compared the surgical results of 44 cystic VSs with 151 solid VSs, and found that cystic tumors were associated with a greater risk of poor facial never outcome. Benech et al. (2) demonstrated a tendency toward a worse facial nerve outcome in their III-IV grade cystic VSs when compared with solid VSs of matching size.

The major factor influencing the postoperative facial function is the tumor size. A good facial function is achieved in most small lesion and in a much lower proportion of cases with large tumors. As reported by Wiet et al. (24), the risk of facial nerve dysfunction in patients with a VS $>3 \mathrm{~cm}$ is 6-fold greater than that in patients with smaller size tumor. Large VSs are often associated with compression of the adjacent cranial nerves and brainstem, the facial nerve is compressed or even infiltrated by the tumor capsule, it is stretched very thin and often adheres tightly to the tumor. Identification and dissection of the facial nerve with preserving its anatomic integrity and function become more difficult in large VSs surgery.

The advantages of the retrosigmoid approach have been discussed by different authors, and good results have published in numerous papers $(8,25,27)$. In this study, we applied this approach to remove 103 large VSs including 36 cystic and 67 solid tumors. The facial nerve outcome was favorable in $70.1 \%$ of the total patients and $73.1 \%$ of patients with cystic VS at 1 year after surgery. The results indicated that the facial nerve function could be effective preserved by this approach, even for large cystic VSs.

The injury of the facial nerve during operations for removal of VSs can be caused by a number of possible mechanisms. The main causes include direct trauma or nerve stretching as well as compromise of the vascular supply to the facial nerve during surgery (18).Various factors that lead to unfavorable facial nerve function in cystic VSs include stronger adhesion of cystic tumor to the facial nerve, hypervascular solid portions of the tumor, relatively uncertain position of facial nerves, and more difficulty in maintaining the subarachnoid dissection plane $(2,11,12,14,23)$. Although some of these factors are also often encountered during operation of large solid VSs, it seems they occur with increased frequency during resection of cystic VSs (14).

Large cystic VSs are characterized by serious adhesion or absence of a clear histologic cleavage plane at tumor-nerve interface. Thus, a decent dissection may increase the risk of direct trauma or nerve stretching, and may damage the blood supply since most of the microvascular blood supply to the facial nerve lie in the subarachnoid space. Some authors favor subtotal tumor removal to minimize the risk of injury to the facial nerve in large VS as well as cystic VS surgery $(14,27)$. Piccirillo $\mathrm{E}$ et al. (14) reported that only subtotal resection could offer the cystic VS patients a normal facial nerve outcome, when a dissection plane could not be developed between the cyst wall and the nerve. In our series, there was no significant difference in facial nerve outcomes between cystic and solid tumors, despite total removal rate in cystic VSs is significantly lower than in solid tumors. However, it must be noted that many studies have found that cystic tumors are associated with unfavorable facial nerve outcomes, and we also agree that extensive adhesion in cystic VSs increases the risk of facial nerve damage. Thus, we attribute the similar results to our appropriate intraoperative management.

Cystic VSs represent a heterogeneous group of tumors in terms of the existence of an arachnoid dissection plane, location of the cysts, thickness of the cyst wall, number of the cysts and degree of the cyst change. All these variables can affect the surgical outcomes, and the degree of the cyst change was one of the most importance prognostic factors for postoperative results (10). According to preoperative image and intraoperative findings, we classified cystic VSs into four subtypes to help with preoperative assessment. In our experience, partial cystic VSs with central or posterior located cyst tend to be easily excised with a better facial nerve function (Figure $2 A, B, C$ ). As previous studies reported, special care should be taken to removal entire cystic VSs (Figure 5 A-F, Figure $6 \mathrm{~A}-\mathrm{E}$ ), because the arachnoidal plane is extremely difficult to maintain in this nature by the fact that the thin tumor wall offers low resistance to dissection. Furthermore, in multicystic entire cystic VS (Figure 6), the separation strips within tumor may confuse with the tumor capsule during the surgery. In our cystic series, four cases failed in facial nerve preservation, including two cases of entire cystic VS and two cases of partial cystic VSs with anterior or medial located cysts (Figure $3 A, B, C$, Figure $4 A, B, C$ ).

As complete resection of large cystic VSs may carry a risk of long-term suboptimal facial nerve outcome, and near total or subtotal resection could afford a better facial nerve function, we agree with Piccirillo $E$ and others that when the tumor is adherent to the facial nerve and a dissection plane cannot be developed between the cyst wall and the nerve, near total or subtotal resection, leaving portions of the cyst walls on the facial nerve is recommended. In the current literature, many authors do not believe that complete tumor resection is 


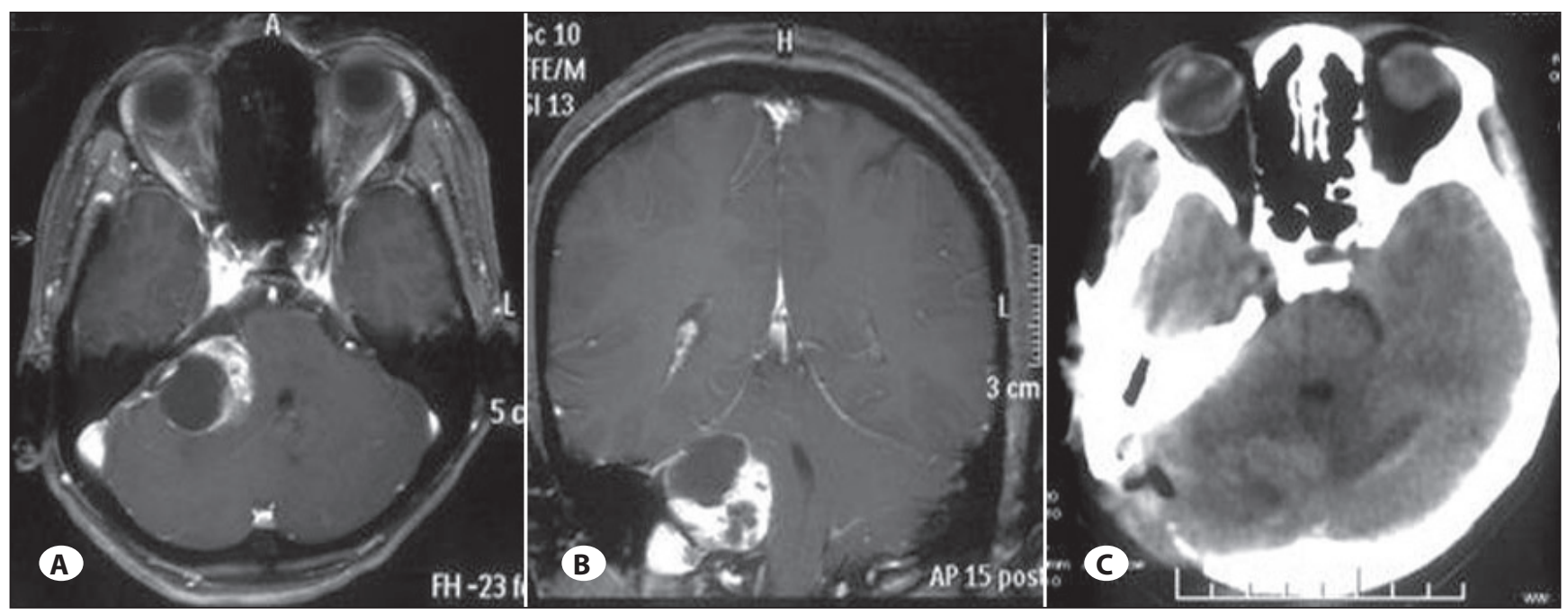

Figure 2: Case illustration. A-B) Preoperative MRI images show a TypeA1 cystic VS with posterior located cyst. C) Postoperative CT image of the same patient.

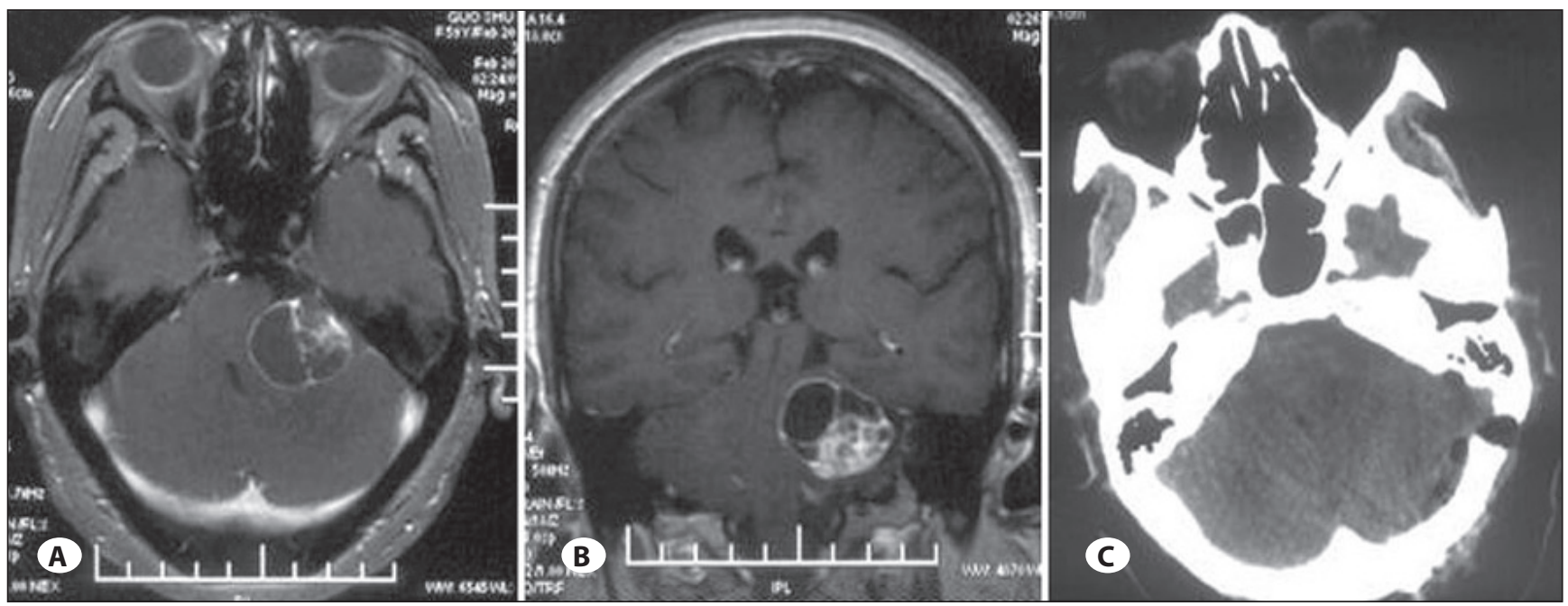

Figure 3: Case illustration. A-B) Preoperative MRI images show a TypeA1 cystic VS with medial located cyst. C) Postoperative CT image of the same patient.
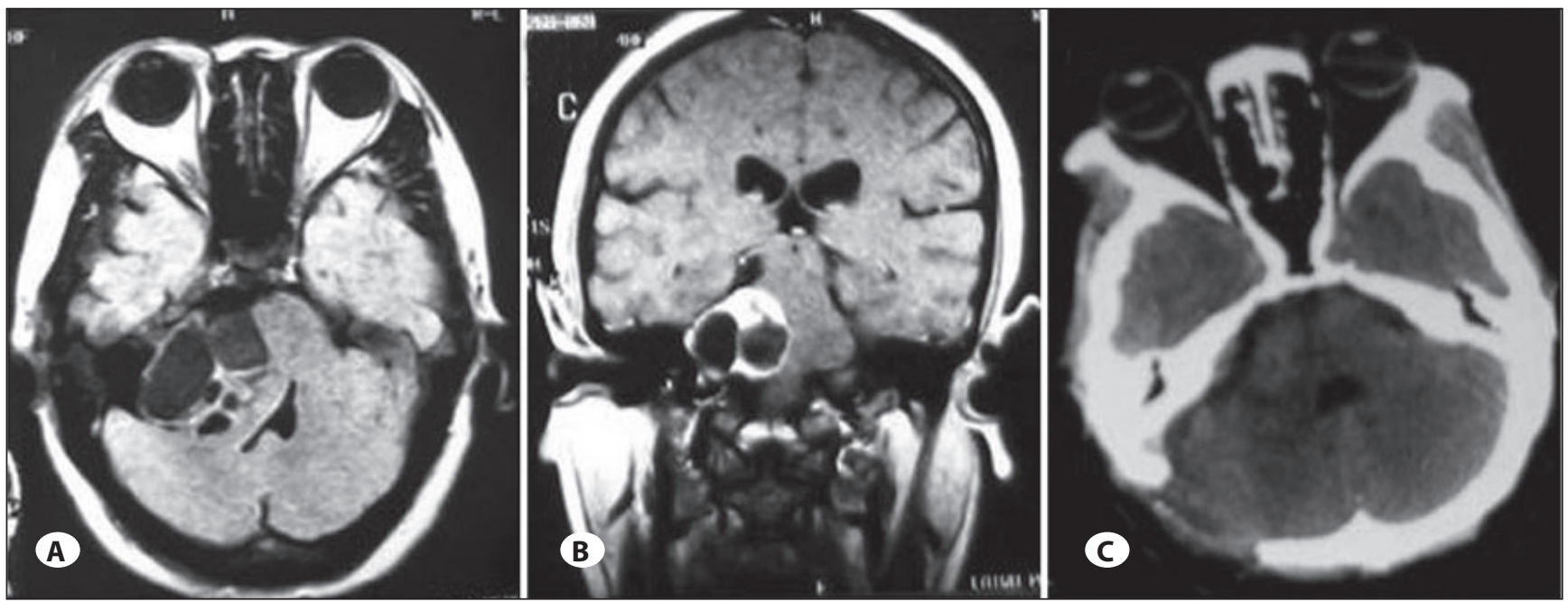

Figure 4: Case illustration. A-B) Preoperative MRI images show a TypeA2 cystic VS with anterior located cysts, C) Postoperative CT image of the same patient. 
indicated in all cases of cystic VS, preservation of facial nerve function should be prioritized over total resection of tumor for the severe psychosocial impact of disfiguring facial palsy on the patients $(2,12,14,15)$.

There seemed to be no functional difference in outcome between cystic VS patients and solid VS patients, even though one cystic VS patient died of perioperative cerebellopontine angle hemorrhage. Cerebellopontine angle hemorrhage was one of the main causes of death in operation of larger VS (16). Samii and Matthies reported the patients with cystic tumors were at major risk of postoperative CPA hemorrhage (17). Injury to the venous structures or excessive removal of cyst wall leading small bleeding has been believed to be responsible for insidious postoperative bleeding. Compared to other reports (16), the rate of postoperative lower cranial nerve dysfunction is higher in our study. However, it may be related to our higher percentage of patients with preoperative facial palsy and obstructive hydrocephalus.

\section{CONCLUSION}

In a majority of patients with large cystic VSs, favorable facial nerve function can be attained by surgical treatment via retrosigmoid approach. Special care should be taken to removal entire cystic VSs as well as partial cystic VSs with anterior or medial located cysts. When a dissection plane could not be developed between the cyst wall and the facial nerve, near total or subtotal resection, leaving portions of cyst wall attached to the facial nerve, is of benefit for facial nerve outcomes.
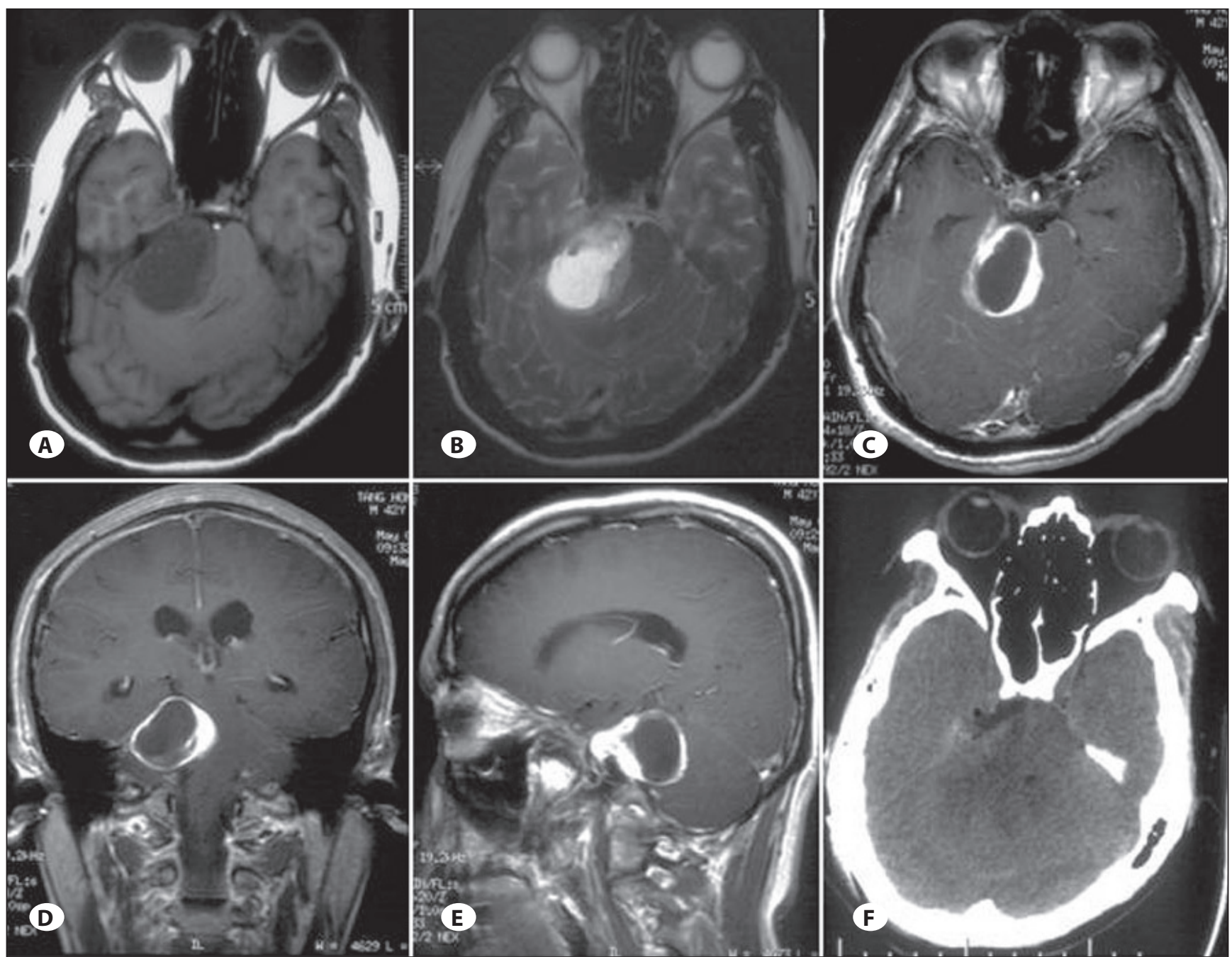

Figure 5: Case illustration. A-E) Preoperative MRI images show a TypeB1 cystic VS. F) Postoperative CT image of the same patient. 

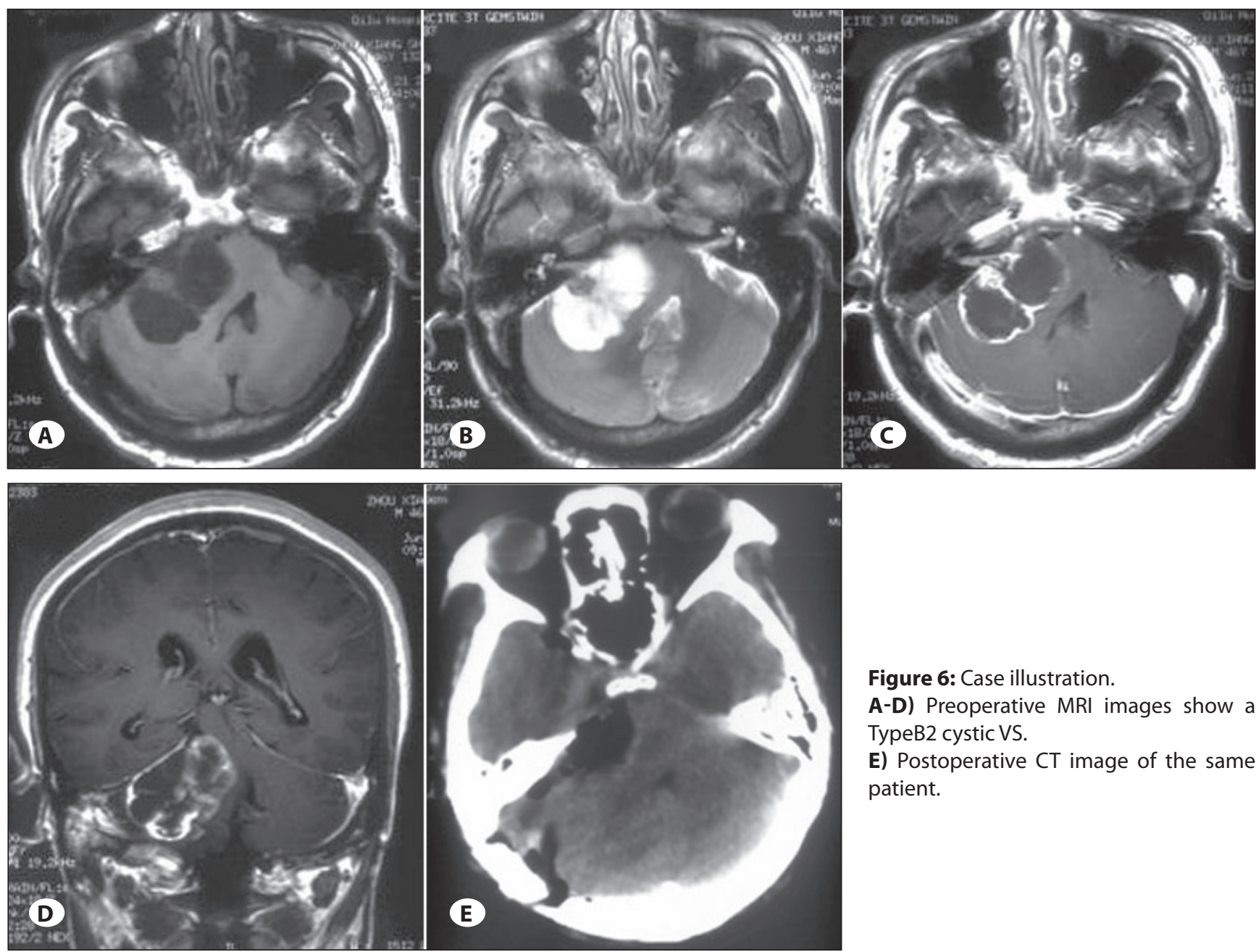

Figure 6: Case illustration.

A-D) Preoperative MRI images show a TypeB2 cystic VS.

E) Postoperative CT image of the same patient.

\section{REFERENCES}

1. Anderson DE, Leonetti J, Wind JJ, Cribari D, Fahey K: Resection of large vestibular schwannomas: Facial nerve preservation in the context of surgical approach and patient-assessed outcome. J Neurosurg 102:643-649, 2005

2. Benech F, Perez R, Fontanella MM, Morra B, Albera R, Ducati A: Cystic versus solid vestibular schwannomas: A series of 80 grade III-IV patients. Neurosurg Rev 28:209-213, 2005

3. Chen L, Chen L, Liu L, Ling F, Yuan X, Fang J, Liu Y: Vestibular schwannoma microsurgery with special reference to facial nerve preservation. Clin Neurol Neurosurg 111: 47-53, 2009

4. Fundova $\mathrm{P}$, Charabi $\mathrm{S}$, Tos $\mathrm{M}$, Thomsen J: Cystic vestibular schwannoma: Surgical outcome. J Laryngol Otol 114: 935-939, 2000

5. House JW, Brackmann DE: Facial nerve grading system. Otolaryngol Head Neck Surg 93:146-147, 1985

6. Jain VK, Mehrotra N, Sahu RN, Behari S, Banerji D, Chhabra DK: Surgery of vestibular schwannomas: An institutional experience. Neurology India 53:41-45, 2005

7. Jones SE, Baguley DM, Moffat DA: Are facial nerve outcomes worse following surgery for cystic vestibular schwannoma? Skull Base 17:281-284, 2007
8. Jung S, Kang SS, Kim TS, Kim HJ, Jeong SK, Kim SC: Current surgical results of retrosigmoid approach in extralarge vestibular schwannomas. Surg Neurol 53:370-378, 2000

9. Lanman TH, Brackmann DE, Hitselberger WE, Subin B: Report of 190 consecutive cases of large acoustic tumors (vestibular schwannoma) removed via the translabyrinthine approach. J Neurosurg 90:617-623, 1999

10. Matthies C, Samii M, Krebs S: Management of vestibular schwannomas (Acoustic Neuromas): Radiological features in 202 cases-their value for diagnosis and their predictive importance. Neurosurgery 40:469-482, 1997

11. Mehrotra N, Behari S, Pal L, Banerji D, Sahu RN, Jain VK: Giant vestibular schwannomas: Focusing on the differences between the solid and the cystic variants. $\mathrm{Br} J$ Neurosurg 22:550-556, 2008

12. Muzumdar DP, Goel A, Pakhmode CK: Multicystic acoustic neurinoma: Report of two cases. J Clin Neurosci 9:453-455, 2002

13. Park CK, Jung HW, Kim JE, Son YJ, Paek SH, Kim DG: Therapeutic strategy for large vestibular schwannomas. J Neurooncol 77(2):167-171, 2006 
14. Piccirillo E, Wiet MR, Flanagan S, Dispenza F, Giannuzzi A, Mancini F, Sanna M: Cystic vestibular schwannoma: Classification, management, and facial nerve outcomes. Otol Neurotol 30:826-834, 2009

15. Raftopoulos C, Abu Serieh B, Duprez T, Docquier MA, Guérit JM: Microsurgical results with large vestibular schwannomas with preservation of facial and cochlear nerve function as the primary aim. Acta Neurochir 147:697-706, 2005

16. Roche PH, Ribeiro T, Fournier HD, Thomassin JM: Vestibular schwannomas: Complications of microsurgery. Prog Neurol Surg 21:214-221, 2008

17. Samii M, Matthies C: Management of 1000 vestibular schwannomas (acoustic neuromas): Surgical management and results with an emphasis on complications and how to avoid them. Neurosurgery 40:11-23, 1997

18. Sampath P, Holliday MJ, Brem H, Niparko JK, Long DM: Facial nerve injury in acoustic neuroma (vestibular schwannoma) surgery: Etiology and prevention. J Neurosurg 87:60-66, 1997

19. Seol HJ, Kim CH, Park CK, Kim CH, Kim DG, Chung YS, Jung HW: Optimal extent of resection in vestibular schwannoma surgery: Relationship to recurrence and facial nerve preservation. Neurol Med Chir Tokyo 46:176-181, 2006

20. Sinha S, Sharma BS: Cystic acoustic neuromas: Surgical outcome in a series of 58 patients. J Clin Neurosci 15:511-515, 2008
21. Todd Hillman, Douglas A. Chen, Moises A: Arriaga, Matthew Quigley: Facial nerve function and hearing preservation acoustic tumor surgery: Does the approach matter? Otolaryngology-Head and Neck Surgery 142:115-119, 2010

22. Veronezi RJ, Fernandes YB, Borges G, Ramina R: Longterm facial nerve clinical evaluation following vestibular schwannoma surgery. Arq Neuropsiquiatr 66:194-198, 2008

23. Wandong S, Meng L, Xingang L, Yuguang L: Cystic acoustic neuroma. J Clin Neurosci 12:253-255, 2005

24. Wiet RJ, Mamikoglu B, Odom L, Hoistad DL: Long-term results of the first 500 cases of acoustic neuroma surgery. Otolaryngol Head Neck Surg 124:645-651, 2001

25. Yamakami I, Uchino Y, Kobayashi E, Yamaura A, Oka N: Removal of large acoustic neurinomas (vestibular schwannomas) by the retrosigmoid approach with no mortality and minimal morbidity. J Neurol Neurosurg Psychiatry 75: 453-458, 2004

26. Zhang X, Fei Z, Chen YJ, Fu LA, Zhang JN, Liu WP, He XS, Jiang $X F$ : Facial nerve function after excision of large acoustic neuromas via the suboccipital retrosigmoid approach. J Clin Neurosci 12:405-408, 2005

27. Zhao X, Wang Z, Ji Y, Wang C, Yu R, Ding X, Wei S: Long-term facial nerve function evaluation following surgery for large acoustic neuromas via retrosigmoid transmeatal approach. Acta Neurochir (Wien) 152:1647-1652, 2010 